\title{
RESTRICTION FRAGMENT LENGTH POLYMORPHISMS OF THE CYP11B1 GENE IN THE JAPANESE POPULATION
}

\author{
Yuichi Nakagawa, ${ }^{1}$ Hiromi Takeuchi, ${ }^{1}$ Akira Kubota, ${ }^{1}$ \\ Yutaka NaKahorI, ${ }^{2}$ Yasuo NaKagome, ${ }^{2}$ Yoshio IGarashi, ${ }^{1}$ \\ and Masao YAMADA ${ }^{3}$ \\ ${ }^{1}$ Department of Pediatrics, Hamamatsu University School of Medicine, \\ Handa-cho, Hamamatsu 431-31, Japan \\ ${ }^{2}$ Department of Human Genetics, School of International Healh, University of Tokyo, \\ Bunkyo-ku, Tokyo 154, Japan \\ ${ }^{3}$ Department of Congenital Abnormalities Research, National Children's \\ Medical Research Center, Taishido, Setagaya-ku, Tokyo 154, Japan
}

\begin{abstract}
Summary Restriction fragment length polymorphisms (RFLPs) of the CYP11B1 gene were studied in Japanese using cDNA clone P450c11 as a probe. Genomic DNAs from 60 unrelated Japanese individuals were digested with 8 different restriction enzymes and analyzed by Southern blot hybridization. Two RFLPs were detected in MspI digests of the DNA. One (A) was characterized by polymorphic bands at 3.4 and 2.5 kilobasepairs $(\mathrm{kb})$ and the other $(\mathrm{B})$ by polymorphic bands at 1.7 and $1.2 \mathrm{~kb}$. The third RFLP was observed in $P v u$ II-digested samples and was polymorphic at 5.8 and $4.0 \mathrm{~kb}$ bands. Two of the three RFLPs found, RFLP (A) and (C), have not been described in the only previous report which was based on Caucasian samples. We also examined the RFLPs of a 3 generation family of $11 \beta$-hydroxylase deficiency caused by an abnormality of the CYP11B1 gene. All the family members were homozygous in all three RFLPs and was thus not informative.

Key Words CYP11B1, RFLP, congenital adrenal hyperplasia, ethnic group
\end{abstract}

\section{INTRODUCTION}

Steroid $11 \beta$-hydroxylase ( $\mathrm{P} 450 \mathrm{cll})$ is a mitochondrial cytochrome $\mathrm{P} 450$ enzyme necessary for cortisol biosynthesis. The CYP11Bl gene which codes the P450c11

Received December 24, 1992; Revised Accepted March 12, 1993. 
enzyme is located along with the highly homologous CYP11B2 gene on chromosome 8q22 (Chua et al., 1987; Mornet et al., 1989).

Deficiency of $11 \beta$-hydroxylase causes a hypertensive form of congenital adrenal hyperplasia. Classic 11 $\beta$-hydroxylase (P450c11) deficiency accounts for 5-8\% of cases of congenital adrenal hyperplasia in the Caucasian population (Zachmann et al., 1983) but only $1 \%$ in the Japanese population (Suwa, 1980). The difference in the frequency may be due to the difference of the genetic background in the two ethnic groups.

Globerman et al. (1988) described a restriction fragment length polymorphism (RFLP) of the CYP11B1 locus. They based their study on Caucasian samples but it is unknown whether RFLP applies to other ethnic groups. We attempted to analyze the RFLPs of CYP11B1 in the Japanese population using 8 different restriction enzymes including the one described by Globerman et al. (1988).

\section{MATERIALS AND METHODS}

High molecularweight DNA was extracted from peripheral blood leukocytes of 60 unrelated Japanese individuals and 7 members of a 3-generation family with $11 \beta$-hydroxylase deficiency. The DNA ( $4 \mu \mathrm{g}$ each) was digested with one of 8 restriction enzymes (BamHI, BglII, EcoRI, HindIII, MspI, Pst I, PvuII, or TaqI (New England Biolabs)) and separated by electrophoresis on a $0.7 \%$ agarose gel in TBE buffer ( $89 \mathrm{~mm}$ Tris-borate, $2 \mathrm{mM}$ EDTA, pH 8.0). The DNA samples were then transferred to a nitrocellulose membrane filter (Hybond-C, Amersham) by blotting (Southern, 1975). The P450c11 cDNA probe was labeled by using a nick translation kit (Bethesda Research Laboratories, Gaithersburg, MD) and $\left[\alpha{ }^{32} \mathrm{P}\right] \mathrm{dCTP}(3,000 \mathrm{Ci} / \mathrm{mmol}$; Dupont-New England Nuclear, Boston, MA). Prehybridization of the filters, hybridization to the ${ }^{32} \mathrm{P}$-labeled P450c1l cDNA probe and posthybridization washes followed the procedure of Sambrook et al. (1989). Hybridizing bands were detected by autoradiography at $-80^{\circ} \mathrm{C}$ using Fuji $\mathrm{AIF}$ FX film (Fuji Photo Film, Kanagawa, Jpn.) and Dupont Lightning Plus intensifying screens (DuPont, Wilmongton, DE).

The P450c11 cDNA probe, clone pH11F2, was kindly supplied by Dr. White.

\section{RESULTS AND DISCUSSION}

P450cll cDNA revealed two RFLPs when digested with MspI. RFLP (A) consisted of $3.4 \mathrm{~kb}$ (A1) and $2.5 \mathrm{~kb}$ (A2) bands. RFLP (B) consisted of $1.7 \mathrm{~kb}$ (B1) and $1.2 \mathrm{~kb}$ (B2) bands (Fig. 1). RFLP (A) in 60 unrelated Japanese individuals showed genotype A1Al in 17 individuals $(28 \%)$, A1A2 in 36 cases $(60 \%)$ and A2A2 in $7(12 \%)$. RFLP (B) in 60 unrelated Japanese individuals showed genotype $\mathrm{B} 1 \mathrm{~B} 2$ in 10 cases $(17 \%)$ and $\mathrm{B} 2 \mathrm{~B} 2$ in $50(83 \%)$. B1B1 was not observed.

One RFLP (RFLP(C)) was detected with polymorphic bands of 5.8 and 4.0 


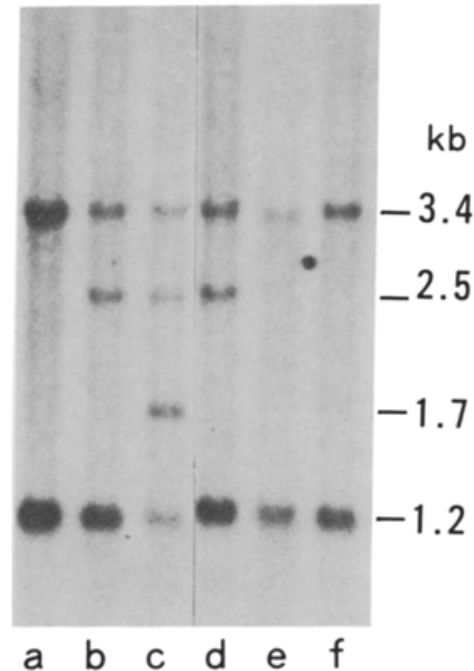

Fig. 1.

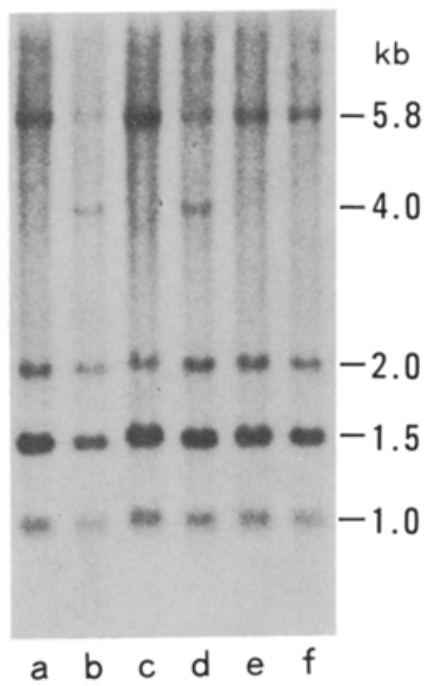

Fig. 2.

Fig. 1. RFLPs detected by MspI digests. Genomic DNA obtained from peripheral blood was digested with $M s p I$ and hybridized with ${ }^{32}$ P-labeled P450c11 cDNA. Two RFLPs were detected. One was characterized by polymorphic bands at 3.4 and $2.5 \mathrm{~kb}$ (RFLP (A)) and the other by bands at 1.7 and $1.2 \mathrm{~kb}$ (RFLP (B)). Lanes a-d show data from normal individuals and lanes $\mathrm{e}-\mathrm{f}$ from patients with $11 \beta$ hydroxylase deficiency.

Fig. 2. RFLP(C) detected by $P v u I I$ digestion. Genomic DNA prepared from peripheral blood was digested with $P y u I I$ and hybridized with ${ }^{32}$ P-labeled P450c11 cDNA. The RFLP was characterized by polymorphic bands at 5.8 and $4.0 \mathrm{~kb}$. Lanes $a-d$ show data from normal indviduals and lanes $\mathrm{e}-\mathrm{f}$ from patients with $11 \beta$ hydroxylase deficiency.

$\mathrm{kb}$ (Fig. 2) when digested with $P v u$ II. Of 60 unrelated Japanese individuals, 44 (73 $\%$ ) were homozygous for the $5.8 \mathrm{~kb}$ band and $16(27 \%)$ were heterozygous. No homozygote for the $4.0 \mathrm{~kb}$ band was detected. The observed frequencies of individual genotypes did not differ significantly from those expected from HardyWeinberg equilibrium in all three RFLPs. We did not find any RFLPs with the restriction enzymes BamHI, BglII, EcoRI, HindIII, Pst I, and TaqI.

We examined a family with $11 \beta$-hydroxylase deficiency for the three RFLPs which were found above (A, B, and $\mathrm{C}$ ). All members were homozygous in all the RFLPs. This information thus was not informative in genetic counselling (Fig. 3).

Out of the three RFLPs described in the present study, only RFLP (B) has been described in the literature (Globerman et al., 1988). Their Caucasian samples did not show RFLP (A). It is possible that they did not find RFLP (C) because they simply did not try $P v u I T$. There is a difference in the frequency of $11 \beta$-hydroxylase deficiency caused by the P450c11 abnormality in the Caucasian and Japanese populations. Classic $11 \beta$-hydroxylase deficiency comprises $5-8 \%$ of cases of con- 

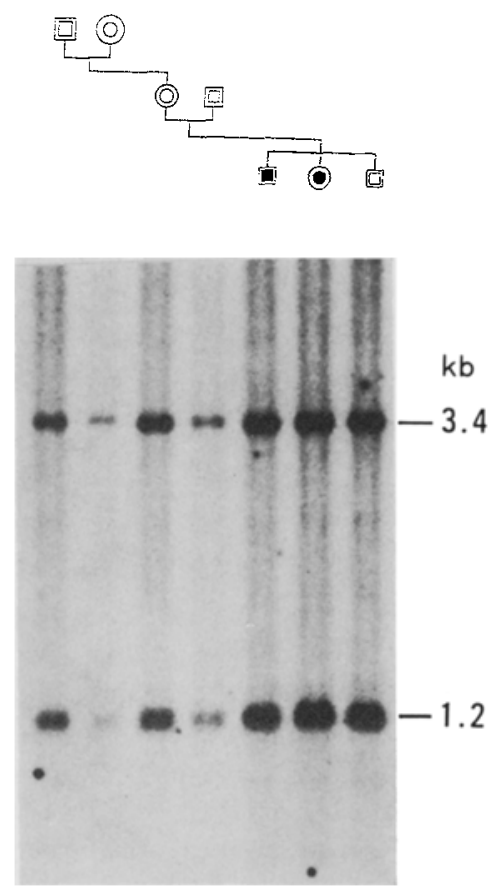

Fig. 3. RFLP pattern by $M s p I$ digestion in a family with $11 \beta$-hydroxylase deficiency. All members were hlomozygoes for both the RFLP(A) and (B) loci.

genital adrenal hyperplasia in the Caucasian population (Zachmann et al., 1983) but only $1 \%$ in the Japanese population (Suwa, 1980). The difference of RFLPs may reffect, a difference in the $11 \beta$-hydroxylase region between the two races. Further studies are needed to clarify the cause of the ethnic difference in the frequency of $11 \beta$-hydroxylase deficiency.

Acknowledgments We are grateful to Dr. P.C. White for providing us with probe pH11F2. We would also like to thank Mr. Shinichi Yokota for his technical assistance.

This work was supported in part by a grant from the Research Committee on Disorders of Adrenal Hormones under the auspices of the Ministry of Health and Welfare of Japan.

\section{REFERENCES}

Chua SC, Szabo P, Vitek A, Grzeschik KH, John M, White PC (1987): Cloning of cDNA encoding steroid 11 $\beta$-hydroxylase (P450c11). Proc Natl Acad Sci USA 84: 7193-7197

Globerman H, Rosler A, Theodor R, New MI, White PC (1988): An inherited defect in aldosterone biosynthesis caused by a mutation in or near the gene for steroid $11 \beta$-hydroxylase. New Engl J Med 319: 1193-1197

Mornet E, Dupont J, Vitek A, White PC (1989): Characterization of two genes encoding human steroid 11 $\beta$-hydroxylase (P-45011 $)$. J Biol Chem 264: 20961-20967

Sambrook J, Fritsch EF, Maniatis T (eds) (1989): Molecular cloning. A Laboratory Manual, Second ed., Cold Spring Harbor Laboratory Press, Cold Spring Harbor, New York 
Southern EM (1975): Detection of specific sequence among DNA fragments separated by gel electrophoresis. J Mol Biol 78: 503-507

Suwa S. (1980): Investigation on the actual state of congenital adrenal hyperplasia in Japan. Horumon to Rinsho 28: 731-738 (in Japanese)

Zachmann M, Tassinari D, Prader A (1983): Clinical and biochemical variability of congenital adrenal hyperplasia due to $11 \beta$-hydroxylase deficiency. J Clin Endocrinol Metab 56: 222-229

Vol. 38, No. 2, 1993 